\title{
Should Paediatricians be Familiar with Osteoporosis?
}

\section{Abdulaziz N Al Jurayyan', Rushaid NA Al-Jurayyan², and Nasir AM Al-Jurayyan ${ }^{3 *}$}

${ }^{1}$ Department of Orthopaedic Surgery, College of Medicine and King Khalid University Hospital, King Saud University, Riyadh, Saudi Arabia

${ }^{2}$ Department of Radiology and Medical Imaging, College of Medicine and King Khalid University Hospital, King Saud University, Riyadh, Saudi Arabia

${ }^{3}$ Department of Paediatrics, College of Medicine and King Khalid University Hospital, King Saud University, Riyadh, Saudi Arabia

\begin{abstract}
Osteoporosis is recognized as an adult metabolic bone disease, and constitutes a major public health problem world-wide. It is, currently, emerging as a newly recognized problem in children and adolescent. Increased awareness and availability of Dual-Energy X-Ray Absorptiometry (DEXA) facilitate diagnosis. Paediatricians should be familiar with all aspects of the disease and contribute to its prevention and management.
\end{abstract}

In this brief review, childhood osteoporosis is presented to highlight its pathogenesis, diagnosis and management.

Keywords: Osteoporosis; Children; DEXA; Causes; Risk factors

Abbreviations: BMD: Bone Mineral Density; DEXA: Dual Energy X-ray Absorptiometry

\section{Key Points}

- Although osteoporosis is considered to be a disease of adults, recently it is emerging as a newly recognized health problem in children and adolescence.

- Osteoporosis is a systemic bone disease characterized by low bone mineral density (mass), micro architectural deterioration, and a subsequent increase in bone fragility.

- Peak bone mass is achieved during childhood and adolescence, therefore, every effort should be taken by paediatrician to prevent the disease.

- Bone Mineral Density (BMD) assessment with Dual-Energy $\mathrm{X}$-Ray Absorptiometry (DEXA) is the most appropriate method in diagnosis.

\section{Introduction}

Osteoporosis is the most common metabolic bone disorder in adults, and constitutes a major public health problem worldwide. For a long period of time it has been recognized as a disease of adults, however, in recent years osteoporosis is emerging as a newly recognized problem in children and adolescents [1]. In contrast to osteomalacia where the problem lies in poor bone mineralization with preserved, main architecture, osteoporosis is defined as a systemic skeletal disease characterized by low bone mass and micro architectural deterioration of bone tissue with a consequent increase in bone fragility and susceptibility to fractures $[1,2]$.

Bone consists of a collagen matrix into which calcium, in the form of hydroxyapatite, is deposited. The accumulation and maintenance of the substance of bone is the result of a continuous process of formation, predominantly mediated by osteoblasts, and resorption, facilitated by osteoblasts. During infancy, childhood and adolescence, formation predominates, leading to a net increased in bone mass and size, with infancy and adolescence being periods of a particularly rapid formation. Peak bone mass is achieved shortly after completion of puberty and normally remains stable until the third decade of life with a steady decline thereafter, about one percent per year. Therefore, childhood period can have an important short term impact on bone health, as well as potential for long-term morbidity $[1,3]$.

Several factors play a role in determining peak bone mass in an individual, and should always be considered in assessment. Intrinsic factors, which cannot be modified and include genetic background, race, and gender, accounts for the majority. Males achieve a higher peak bone mass, and aging men have a lower incidence of osteoporotic fractures than women [1-6]. On the other hand, environmental, nutritional and physical activity are some of the extrinsic factors which can be modified and constitute a major and important step in prevention [3,4,7-10] chronic illnesses can be other major factors. Healthcare providers, therefore, can influence and modify these factors, by increased awareness and contribute actively to its prevention and share in the appropriate management.

\section{Pathogenesis}

Symptomatic osteoporosis in an otherwise healthy child or adolescent is extremely rare, though cases of idiopathic juvenile osteoporosis have been reported $[3,4,11,12]$. Rather, childhood osteoporosis is more likely to be seen in the setting of chronic illness [Table 1 $\$$ This is not surprising, since the impact of illness and treatment is being increasingly recognized in survivors of severe paediatric disease [3,4,13,14-16].

\section{Diagnosis and the Role of Dual-Energy X-ray Absorptiometry (DEXA)}

There is strong evidence that, in adults, the Bone Mineral Density (BMD) value is a good predictor of the fracture risk, and it has been calculated that fracture risk approximately doubles with each $1 \mathrm{SD}$ below the average value of sex-matched healthy young adults. On this bases a BMD less than $2.5 \mathrm{SD}$ (T-score <-2.5) is considered as osteoporosis. However, in children and adolescents, the interpretation of densitometric data is difficult because the normal BMD values to be used is continuously changing with age, and in addition, depend on several variables, such as gender, pubertal stage, body size, skeletal maturation, and ethnicity. Usually, the reference population is one of

*Corresponding author: Nasir AM Al-Jurayyan, Professor of Paediatrics and Consultant Endocrinologist, Department of Paediatrics (39), College of Medicine, King Saud University, P.O. Box 2925, Riyadh 11461, Saudi Arabia, Tel: +966-1 467-0807; Fax: +966-1-467-9463; E-mail: njurayyan@ksu.edu.sa

Received July 07, 2012; Accepted September 24, 2012; Published September 26, 2012

Citation: Al Jurayyan AN, Al-Jurayyan RNA, Al-Jurayyan NAM (2012) Should Paediatricians be Familiar with Osteoporosis? Primary Health Care 2:122. doi:10.4172/2167-1079.1000122

Copyright: (c) 2012 Al Jurayyan, et al. This is an open-access article distributed under the terms of the Creative Commons Attribution License, which permits unrestricted use, distribution, and reproduction in any medium, provided the original author and source are credited. 


\begin{tabular}{|c|c|}
\hline $\begin{array}{l}\text { Idiopathic juvenile } \\
\text { osteoporosis }\end{array}$ & \\
\hline $\begin{array}{l}\text { Heritable disorders of } \\
\text { connective tissue }\end{array}$ & $\begin{array}{l}\text { Osteogenesis imperfect, Ehler-Danlossyndrome, } \\
\text { Marfan syndrome, etc. }\end{array}$ \\
\hline Chronic illness & $\begin{array}{l}\text { Respiratory, renal, liver, gastro-intestinal disorders, } \\
\text { cancer, anorexia nervosa, etc. }\end{array}$ \\
\hline Neuromuscular disorders & Cerebral palsy, Duchenne muscular dystrophy \\
\hline Endocrine diseases & $\begin{array}{l}\text { Delayed puberty, hypo or hyperthyroidism, Turner's } \\
\text { syndrome, hypogonadism, diabetes, growth } \\
\text { hormone deficiency, Cushing syndrome, etc. }\end{array}$ \\
\hline \multicolumn{2}{|l|}{$\begin{array}{l}\text { Inborn Errors of } \\
\text { Metabolism }\end{array}$} \\
\hline Medications (Drugs) & $\begin{array}{l}\text { Anti-convulsant, methotrexate, glucocorticoids, } \\
\text { cyclosphorine, etc. }\end{array}$ \\
\hline
\end{tabular}

Table 1: Main causes of osteoporosis.

ethnicity, gender and age matched healthy control and the index used is the difference between the observed BMD and the reference (normal) $\mathrm{BMD}$ value expressed in SD units, such index is called $\mathrm{Z}$-score, and the only one to be used in the assessment of growing children. However, this is not always satisfactory as it should be corrected to height and puberted age. Also the variation in machines should be given consideration as the different data are not interconvertable. Most expert diagnose osteoporosis in children on the basis of low BMD value with a Z-score below -2 , couples with the presence of at least one fragility fracture $[4,9,16-18]$.

In the paediatric population, bone metabolism markers are in conclusive and should not be relied upon to make important clinical decision $[19,20]$. Many of the markers have diurnal variation and all are strongly influenced by puberty. In addition, there are limited pediatric reference ranges available for many of the newer markers. Measurement of BMD with DEXA of children and adolescents with one or more osteoporosis risk factors, e.g. chronic illness, should be strongly considered, and particularly in the setting of fractures with minimal trauma.

\section{Management}

Paediatricians and other healthcare providers should contribute actively in the management of osteoporosis, either in the state of well being or if a child is receiving medical care from a single or multiple sub-specialities. Increased awareness and early detection with understanding the pathogenesis of the disease and knowing the various risk factors and causes, coupled with the promotion of healthy lifestyle habits, as nutrition and exercise, within the limitation imposed by his chronic illness, if any, may be particularly important in the prevention of avoidable long term problems [3,4,7,8,10,20-24].

Once the diagnosis established, based on the appropriate diagnostic means, treatment should be outlined. Risk factors or causes should first be identified and then, whenever possible, reduced or eliminated before prescribing specific drugs. As a general rule, therapeutic interventions must be prudent, beginning with the simplest and safest ones, such as calcium and Vitamin D supplementation, couples with improving nutritional and lifestyles. As suggested by the American Academy of Pediatrics Committee on Nutrition [21]. Among the antiresorptive drugs, only biphosphonates have been successfully used in children, and proved to be save on short term therapy. However, they should be used by an expert, and only after all the alternative measures have been tried without success [3,4,22-34]. Osteoporosis should always be followed up with serial measurements of bone mineral density by DEXA utilizing the same brand.
Finally, the pediatrician should be aware that osteoporosis is not only a disorder of adults but may also concern children afflicted by several disorders with onset in childhood. Improvement and adaption of technique for the determination of bone marrow and strength (DXA, ultrasound) in pediatric population will increase our diagnostic accuracy and provide in valuable tools for assessing different therapies.

\section{References}

1. Bachrach LK (2001) Acquisition of optimal bone mass in childhood and adolescence. Trends Endocrinol Metab 12: 22-28.

2. Bachrach LK, Hastie T, Wang MC, Narasimhan B, Marcus R (1999) Bone mineral acquisition in healthy Asian, Hispanic, black, and Caucasian youth. $A$ longitudinal study. J Clin Endocrinol Metab 84: 4702-4712.

3. Bianchi ML (2007) Osteoporosis in children and adolescents. Bone 41: 486495.

4. Simmons J, Zeitler P, Steelman J (2007) Advances in the diagnosis and treatment of osteoporosis. Adv Pediatr 54: 85-114.

5. Kelly PJ, Twomey L, Sambrook PN, Eisman JA (1990) Sex differences in peak adult bone mineral density. J Bone Miner Res 5: 1169-1175.

6. Seeman E, Hopper JL, Young NR, Formica C, Goss P, et al. (1996) Do genetic factors explain associations between muscle strength, lean mass, and bone density? A twin study. Am J Physiol 270: E320-E327.

7. Cavadini C, Siega-Riz AM, Popkin BM (2000) US adolescent food intake trends from 1965 to 1996. Arch Dis Child 83: 18-24.

8. Lloyd T, Chinchilli VM, Johnson-Rollings N, Kieselhorst K, Eggli DF, et al (2000) Adult female hip bone density reflects teenage sports-exercise patterns but not teenage calcium intake. Pediatrics 106: 40-44.

9. Lehtonen-Veromea MK, Mottonene TT, Nuotio IO, Irjala KM, Leino AE, et al. (2002) Vitamin D and attainment of peak bone mass among peripubertal Finish girls: a 3-year prospective study. Am J Clin Nutr 76: 1446-1453.

10. More J (2008) Children's bone health and meeting calcium needs. J Fam Health Care 18: 22-24.

11. Bishop N (2009) Primary osteoporosis. Endocr Rev 16: 157-169.

12. Dridi M, Nacim A, Bollini G (2008) Juvenile idiopathic osteoporosis. Tunis Med 86: 853-855.

13. Ahmed SF, El Mantaser M (2009) Secondary Osteopprosis. Endocr Rev16: 170-190.

14. Ward LM, Glorieux FH (2003) The spectrum of pediatric osteoporosis. In: Glorieux FH, Pettitor JM, Juppner $\mathrm{H}$, editors. Pediatric bone: biology and diseases. San Diego, CA: Academic Press 401-442.

15. Sylvester FA (2001) An update on bone abnormalities associated with gastrointestinal and liver disease. Endocrinologist 11: 77-85.

16. Baroncelli GI, Bertelloni S, Ceccarelli C, Saggese G (1998) Measurement of volumetric bone mineral density accurately determines degree of lumbar undermineralization in children with growth hormone deficiency. J Clin Endocrinol Metab 83: 3150-3154.

17. Binkovitz LA, Sparke P, Henwood MJ (2007) Pediatric DXA: Clinical applications. Pediatr Radiol 37: 625-635.

18. Bogunovic L, Doyle SM, Vogiatzi MG (2009) Measurement of bone density in pediatric population. Curr Opin Pediatr 21: 77-82.

19. de Ridder CM, Delemarre-Van de Waal HA (1998) Clinical utility of markers of bone turnover in children and adolescents. Curr Opin Pediatr 10: 441-448.

20. Szulc P, Kaufman JM, Delmas PD (2007) Biochemical assessment of bone turnover and bone fragility in men. Osteoporosis Int 18: 1451-1461.

21. Baker SS, Cochran WJ, Flores CA, Georgieff MK, Jacobson MS, et al (1999) American Academy of Pediatrics. Committee on Nutrition. Calcium requirements of infants, children and adolescents. Pediatrics 104: 1152-1157.

22. Faulkner RA, Bailey DA (2007) Osteoporosis: a pediatric concern? Med Sport Sci 51: 1-12.

23. Caradonna P, Riganta D (2009) Bone health as a primary target in the pediatric age. Eur Rev Med Pharmacol Sci 13: 117-128. 
Citation: Al Jurayyan AN, Al-Jurayyan RNA, Al-Jurayyan NAM (2012) Should Paediatricians be Familiar with Osteoporosis? Primary Health Care 2:122. doi:10.4172/2167-1079.1000122

24. Bishop N (2009) Prevention and treatment of osteoporosis in children. Arch Pediatr 16: 596.

25. Shaw NJ (2008) Management of osteoporosis in children. Eur J Endocrinol 159: S33-S39.

26. Bachrach LK (2007) Consensus and controversy regarding osteoporosis in the pediatric population. Endocr Pract 13: 513-520.

27. Landman JO, Hamdy NA, Pauwels EK, Papapoulous SE (1995) Skeletal metabolism in patients with osteoporosis after discontinuation of long-term treatment with oral pamidronate. J Clin endocrinol Metab 80: 3465-3468.

28. Brumsen C, Hamdy NA, Papapoulous SE (1997) Long-term effects of bisphosphonates on the growing skeleton. Studies of young patints with severe osteoporosis. Medicine (Baltimore) 76: 266-283.

29. Glorieux FH, Bishop NJ, Plotkin H, Chabot G, Lanoue G, et al. (1998) Cyclic administration of pamidronate in children with severe osteogenesis imperfecta. N Engl J Med 339: 947-952.

30. Ward L, Tricco AC, Phuong P, Cranney A, Barrowman N, et al. (2007)
Biphosphate therapy for children and adolescent with secondary osteoporosis. Cochrane Databse Sys Rev 4: CD005324.

31. Saag KG, Emkey R, Schnitzer TJ, Brown JP, Hawkins F, et al. (1998) Alendronate for the prevention and treatment of glucocorticoid-induced osteoporosis. Glucocorticoid-Induced Osteoporosis Intervention Study Group. N Engl J Med 339: 292-299.

32. Bianchi ML, Cimaz R, Bardare M, Zulian F, Lepore L, et al. (2000) Efficacy and safety of alendronate for the treatment of osteoporosis in diffuse connective tissue diseases in children: a prospective multicenter study. Arthritis Rheum 43: 1960-1966.

33. Lepore L, Pennesis M, Barbi E, Pozzi R (1991) Treatment and prevention of osteoporosis in juvenile chronic arthritis with disodium clodronate. Clin Exp Rheumatol 9: 33-35.

34. Attard TM, Dhawan A, Kaufman SS, Collier DS, Langnas AN (1998) Use of disodium pamidronate in children with hypercalcemia awaiting liver transplantation. Pedaitr Transplant 2: 157-159. 